\title{
RELACIONES TÓXICAS: LA INSOPORTABLE TENSIÓN ENTRE LAS CLÁUSULAS DE ESTABILIZACIÓN, LA SOBERANÍA ESTATAL Y LOS DERECHOS HUMANOS BAJO EL DERECHO INTERNACIONAL \\ TOXIC RELATIONSHIPS: THE UNBEARABLE TENSION BETWEEN STABILIZATION CLAUSES, STATE SOVEREIGNTY AND HUMAN RIGHTS UNDER INTERNATIONAL LAW
}

\author{
Fabio Núñez del Prado* \\ Exmiembro del Consejo Directivo de THĒMIS \\ Clifford Chance \\ Eugenia Simó García \\ Hogan Lovells
}

Large-scale investments depend on various economic, natural and social factors of the State where they invest. Also, from an economic point of view, once the investment has been made, the financial viability of the project depends, to a large extent, on the investor's ability to capture cash flows. However, investors will always be at some degree of risk.

In this article, the authors examine whether Stabilization Clauses, a widely used risk management device in investment contracts, can affect a State's action in implementing its international human rights and environmental obligations. Specifically, they assess whether Stabilisation Clauses can limit the application and creation of new social or environmental regulations to investment activities during the life of the investment.

KEYWORDS: Stabilization clauses; freezing clause; economic balance clause; investment law; investment.
Las inversiones a gran escala dependen de diversos factores económicos, naturales y sociales del Estado en que se realice la inversión. Asimismo, desde el punto de vista económico, una vez que se ha realizado la inversión, la viabilidad financiera del proyecto depende, en gran medida, de la capacidad que tiene el inversionista de capturar flujos de capital. Sin embargo, los inversionistas siempre se encontrarán con cierto grado de riesgo.

En el presente artículo, los autores examinan si las cláusulas de estabilización, un dispositivo de gestión de riesgos ampliamente utilizado en los contratos de inversión, pueden afectar a la acción de un Estado a la hora de que este implemente sus obligaciones internacionales de derechos humanos y medioambientales. De forma específica, evalúan si las cláusulas de estabilización pueden limitar la aplicación y creación de nuevas regulaciones sociales o ambientales a las actividades de inversión durante la vida de la inversión.

Palabras Clave: Cláusulas de estabilización; cláusula de congelación; cláusula de equilibrio económico; derecho de inversiones; inversión.

* Abogado. Master of Laws (LL.M.) por la Yale Law School. Asociado internacional de Clifford Chance (Washington, Estados Unidos). Contacto: fabio.nunezdelprado@cliffordchance.com.

** Abogada. Máster de Acceso a la Abogacía e International Business Law por la ESADE Law School y Master of Laws (LL.M.) por la Columbia Law School. Asociada internacional de Hogan Lovells (Miami, Estados Unidos). Contacto: es3887@columbia.edu

Nota del Editor: El presente artículo fue recibido por el Consejo Ejecutivo de THËMIS-Revista de Derecho el 8 de abril de 2020, y aceptado el mismo el 16 de julio de 2020. 


\section{INTRODUCCIÓN: MECANISMOS PARA LA ESTABILIZACIÓN DEL MARCO REGULATORIO PARA EL INVERSIONISTA}

Al momento de valorar la posibilidad de hacer una inversión en el extranjero, tras analizar distintos factores y ventajas económicas, el inversionista suele tener en cuenta los siguientes riesgos: (i) el riesgo comercial (por ejemplo, los precios de un activo pueden sobreestimarse o subestimarse); (ii) el riesgo financiero (por ejemplo, las tasas de interés pueden incrementarse o reducirse fuera del rango previsto); (iii) los desastres naturales (por ejemplo, un terremoto puede dañar los activos de la empresa); y, (iv) el riesgo político (por ejemplo, un cambio en la ley disminuye el valor de la inversión) ${ }^{1}$. Como es de esperar, el inversionista siempre se esforzará al máximo para minimizarlos.

Asimismo, desde el punto de vista económico, una vez que se ha realizado la inversión la viabilidad financiera del proyecto depende, en gran medida, de la capacidad que tiene el inversionista de capturar flujos de capital. Sin embargo, durante la vida de la inversión, el inversionista puede ser víctima de las acciones $u$ omisiones del Estado anfitrión que pueden llevar a la destrucción del valor de la misma. Surge, por lo tanto, un riesgo político para el inversionista; por lo que para atraer inversión extranjera nace la necesidad de ofrecerle a estos últimos cierta protección contra futuros cambios en la regulación a través de las cláusulas de estabilización. Dentro de dicha protección, destacan dos mecanismos: (i) los acuerdos ínter-Estados; y, (ii) los contratos entre inversionistas y Estados.

\section{A. Acuerdos ínter-Estados}

Los arreglos legales ínter-Estados constituyen una parte esencial del paquete que un Estado puede ofrecer a potenciales inversionistas extranjeros. No podría ser de otra manera, teniendo en cuenta que los Estados, en su calidad de entes soberanos, definen los términos y condiciones de la inversión extranjera, la distribución de costos y beneficios y (por supuesto) el régimen legal dentro del cual se inserta la inversión ${ }^{2}$.

El acuerdo legal ínter-Estados por antonomasia en el derecho internacional de las inversiones es el Tratado Bilateral de Inversión (en adelante, TBI). Un TBI es un acuerdo entre dos Estados que proporciona una serie de garantías al inversionista extranjero en forma de estándares de actuación que respetará el Estado suscriptor. Dicho aspecto se traduce en un régimen confiable y seguro aplicable a la inversión y a los inversionistas. Sin embargo, para hacer efectivos dichos derechos del inversionista, los TBI suelen incluir mecanismos de solución de controversias que legitiman a las empresas trasnacionales a demandar a los Estados por los supuestos incumplimientos de los tratados.

Pese a que los estándares incluidos en los tratados usualmente se encuentran redactados de forma sucinta y genérica; la jurisprudencia arbitral ha interpretado estos estándares y los ha dotado de un contenido concreto. En este sentido, se han llegado, incluso, a desarrollar doctrinas como la regulatory takings doctrine ${ }^{3}$ (relativa la prohibición de expropiación ilegal) y las expectativas legítimas del inversionista ${ }^{4}$ (relativa al estándar de trato justo y equitativo). Estas doctrinas han contribuido a garantizar el riesgo político del inversionista extranjero frente a cambios en la normativa.

B. Los contratos de inversión entre Estados e inversionistas y las cláusulas de estabilización

Otro mecanismo que garantiza el riesgo político de los inversionistas son los contratos celebrados entre estos mismos y el Estado receptor de la inversión. Dichos contratos recogen obligaciones para ambas partes y fijan los términos en los que se desarrollará la inversión. A su vez, insertan distintos tipos de mecanismos legales que promueven la estabilidad económico-financiera de la inversión.

\footnotetext{
En este contexto, el riesgo político describe los incentivos que los Estados anfitriones tienen para aprobar leyes o reglamentos que extraigan un mayor valor de un proyecto o inversión después de que el inversionista haya incurrido en significativos costos fijos en la construcción de instalaciones, la obtención de mano de obra o el establecimiento de las condiciones necesarias. Sobre el particular, Halabi ha señalado que

a foreign investor will endeavor to minimize at least the following risks after making the decision to invest: commercial risk (prices for a commodity or good may drift above or below estimates), financial risk (interest rates may rise or fall beyond an anticipated range), natural disasters, and political risk - the risk a change in law will diminish the value of the investment (2011, p. 265).

2 En tal sentido, Cotula ha afirmado que "legal arrangements are an important part of the overall package that a country can offer to potential foreign investors. They define the terms and conditions of foreign investment, the way its costs and benefits are shared and, ultimately, the extent to which it contributes to sustainable development goals" (2008, p. 2).

3 Sobre esta, Cotula ha afirmado que "under the regulatory taking doctrine, regulation that undermines the investment's commercial viability may be deemed as a taking of property, and require the host state to pay compensation" (2008, p. 2).

4 Para mayor información, véase a Ghene y Romulo (2017).
} 
Entre otros, cabe resaltar las cláusulas de estabilización y de mitigación del riesgo.

Las cláusulas de estabilización -como su propio nombre lo indica- fijan los términos y condiciones de un proyecto de inversión, contribuyendo así a gestionar el riesgo político y no comercial del inversionista (por ejemplo, fiscal, laboral, regulatorio, aduanero, etcétera). Estas implican un compromiso por parte del gobierno anfitrión de no alterar el marco regulatorio que rige sobre el proyecto, o de compensar al inversionista en el caso de que los cambios alteren el equilibrio económico del contrato 5 .

Por lo general, este tipo de cláusulas son incluidas usualmente en contratos -principalmente de concesión (como los build-operate-transfer agreements) o explotación (como los production sharing agreements) - relacionados con inversiones intensivas en capital y que se van a desarrollar a lo largo de periodos extensos de tiempo (por ejemplo, minería, petróleo, electricidad, agua y alcantarillado, telecomunicaciones, transporte, etcétera). Por ello, las cláusulas de estabilización son especialmente relevantes en los contratos con inversionistas en el sector de la energía y los recursos naturales. La necesidad de desarrollar la inversión a largo plazo para obtener beneficios hace que muchas circunstancias externas a la inversión y el marco regulatorio que afecta al contrato cambien con el tiempo. Esto constituye un riesgo adicional para el inversionista en estos sectores, y de forma especial en países en vías de desarrollo. En estos, la inestabilidad regulatoria y el riesgo político siempre es mayor (al respecto, puede verse Maniruzzaman, 2008, p. 121).

Ahora bien, pese a su frecuencia y a las ventajas que indudablemente presentan para los inversionistas extranjeros, las cláusulas de estabilización han sido objeto de debate prácticamente desde su origen. Aunque las críticas han ido evolucionando en el tiempo, la base siempre ha sido la misma: la soberanía del Estado sobre sus recursos naturales y el desarrollo sostenible. Como veremos, en la actualidad estas dos preocupaciones se encuentran centradas en consideraciones medioambientales y de derechos humanos, con especial énfasis en el sector de la energía y los recursos naturales.

\section{ORIGEN Y EVOLUCIÓN DE LAS CLÁUSULAS DE ESTABILIZACIÓN}

\section{A. Origen e historia}

El origen de las cláusulas de estabilización se encuentra en el período entre la Primera Guerra Mundial y la Segunda Guerra Mundial, cuando las compañías estadounidenses empezaron a utilizarlas habitualmente en los contratos de concesión como respuesta a las nacionalizaciones de empresas en América Latina con el propósito de preservar las concesiones durante toda la vigencia del contrato (Nwaokoro, 2014, p. 103). Desde entonces continúan siendo frecuentes en los contratos entre inversionista y Estados, especialmente en el sector de la energía, tal y como ha expresado el profesor Nwaokoro:

Since then, they have become a staple in international energy contracts, serving as a bulwark to restrict the legislative or administrative power of the State, as sovereign in its country and legislator in its own legal system, to amend the contractual regulation or even to annul the agreement (2014, p. 103) ${ }^{6}$.

A hora bien, en las décadas de los sesenta y setenta, las cláusulas de estabilización continuaron siendo corrientes en la práctica. Durante dicho período, este tipo de cláusulas fueron objeto de un extenso debate sobre su validez y su relación con la soberanía sobre los recursos naturales. En este marco, a medida que los Estados anfitriones comenzaron a exigir mayor soberanía y a reclamar mayor control sobre sus recursos naturales, disminuyó la utilización de las cláusulas de estabilización en la década de los ochenta.

Sin embargo, estas experimentaron un resurgimiento en su uso a partir de la década de los noventa, particularmente en América Latina, donde abundaron las nacionalizaciones por partes de gobiernos estatistas (Nwaokoro, 2014, p. 103).

\section{B. Cláusulas de estabilización en la actualidad}

Actualmente, después de su resurgimiento durante los años noventa, las cláusulas de estabilización continúan siendo muy frecuentes en la práctica. Pese a que en la actualidad continúan siendo

$5 \quad$ Al respecto, en el caso Belenergía c. Italia se señaló expresamente que "[n]either does the Tribunal agree that the contractual 20-year term originally applying to feed in tariffs or the prohibition on unilateral changes could be considered a stabilization clause" (ARB/15/40, 2019, párr. 580).

$6 \quad$ "Desde este entonces, se han vuelto fundamentales en materia de contratos internacionales de energía, sirviendo como una barrera al poder legislativo o administrativo del Estado, como soberano en su país y legislador en su propio sistema, para corregir la regulación contractual o inclusive anular el acuerdo" [traducción libre]. 
criticadas, las circunstancias políticas actuales hacen que, en algunos Estados ricos en recursos naturales, los inversionistas vean necesario obtener algún tipo de garantía contra el riesgo político.

Cabe resaltar que en muchos casos la explotación de estos recursos naturales es fundamental para el desarrollo de dichos países, y que esta misma no puede concretarse sin la entrada de capital y gestión extranjera por la falta de medios que sufren estos países. Sobre el particular, el profesor Emeka ha señalado que lo siguiente:

In Russia, the government of Vladimir Putin acquired Gazprom and revoked a permit for a Shell oil and gas project. In Chad, the Government demanded that international operators Chevron, Exxon Mobil, and Petronas renegotiate their revenue share. In Venezuela, President Hugo Chavez took control over the formerly independent Petróleos de Venezuela (PDVSA) and ordered the IOCs to turn over their majority interest to PDVSA or face complete nationalization of their interests in the oil-rich Orinoco River Basin, forcing out ExxonMobil and ConocoPhillips. In Bolivia, President Evo Morales mobilized the army into Bolivian gas fields and nationalized Bolivia's industry. In Ecuador, the government assumed control of the holdings of the U.S. oil company Occidental, and in Nigeria, the government's attempts to renegotiate PSCs concluded in the 1990s (2008, pp. 1319-1320)

En línea con lo anterior, y en relación con el objeto del presente artículo, las cláusulas de estabilización también se hacen necesarias para los inversionistas en los sectores de la energía y la explotación de recursos naturales; debido a las características intrínsecas de la inversión en el sector (altos costes fijos, la necesidad de desarrollarlas en el largo plazo, etcétera). De hecho, dichos sectores representan casi el $65 \%$ de los contratos estudiados en el proyecto de investigación de la ONU y la Corporación Financiera Internacional (en adelante,
CFI) de 2009 titulado "Cláusulas de estabilización y derechos humanos" la cual constituye uno de los mayores análisis estadísticos de este tipo de contratos hechos hasta la fecha: el Informe UN-IFC8.

No obstante las ventajas para el inversionista, debido a las circunstancias sobre las que operan, en estos sectores la probabilidad de impacto de estas cláusulas sobre el desarrollo sostenible, el derecho ambiental y los derechos humanos es mayor. Este último aspecto ha extendido a la actualidad el debate que existió en la década de los setenta y ochenta con respecto a la idoneidad de dichas cláusulas. Sin perjuicio del debate sobre la soberanía, otras circunstancias han contribuido a la discusión en los últimos tiempos. Entre otras, cabe resaltar el ciclo de aumento de los precios del petróleo y el gas, el repudio de los Estados anfitriones a los acuerdos de producción compartida (production sharing agreements), el debate sobre el medioambiente y los derechos humanos, etcétera. Estos últimos puntos, de forma precisa, serán tratados más adelante en el texto.

\section{TIPOS DE CLÁUSULAS DE ESTABILIZACIÓN}

\section{A. Clasificación de las cláusulas de estabili- zación}

Teniendo en cuenta su contenido, es importante resaltar que existen dos categorías amplias de cláusulas de estabilización ${ }^{9}$. De hecho, su estudio se hace relevante, toda vez que la redacción y los términos de la cláusula de estabilización en particular se vuelven esenciales para evaluar la probabilidad de impactos negativos en los derechos humanos y el medioambiente a través de la limitación de la libertad normativa del Estado.

\section{Cláusulas de congelación}

Las cláusulas de estabilización de mayor alcance son las cláusulas de congelación, cuyo objetivo es garantizar que la ley, el régimen fiscal y otras

"En Rusia, el gobierno de Vladimir Putin adquirió Gazprom y revocó el permiso para un proyecto de petróleo y gas administrado por Shell. En Chad, el gobierno exigió que las empresas internacionales Chevron, Exxon Mobil y Petronas renegociasen su distribución de ganancias. En Venezuela, el presidente Hugo Chávez asumió el control de la originalmente independiente empresa Petróleos de Venezuela (PDVSA) y ordenó a las IOCs a revertir sus intereses a PDVSA o asumir la completa nacionalización de sus inversiones en la cuenca del río Orinoco, la cual es rica en petróleo, forzando la salida de ExxonMobil y ConocoPhillips. En Bolivia, el presidente Evo Morales movilizó al ejército a los campos de gas y nacionalizó la industria boliviana. En Ecuador, el gobierno tomó control de las acciones de la compañía petrolera estadounidense Occidental, y en Nigeria, los intentos del gobierno de renegociar los PSCs concluyeron en los años noventa" [traducción libre].

8 El Informe UN-IFC involucró una encuesta y revisión de setenta y seis contratos de inversión y doce contratos modelo fechados desde los años noventa hasta la actualidad, en distintos sectores económicos y regiones. Para mayor información, véase a Shemberg (2009).

$9 \quad$ En ese sentido, la profesora Annalise Nelson ha señalado expresamente que

there are two basic types of stabilization clauses. "Freezing clauses" act exactly as they sound-they "freeze" the law at the time the contract is executed for that particular investor. Any future changes in legislation or regulation are not applied to the contract. A potentially more nuanced varietal of the stabilization clause is the "economic equilibrium 
condiciones normativas esenciales aplicables a la inversión no se modifiquen durante la vida del proyecto. Por lo tanto, en aplicación de este tipo de cláusulas, la ley vigente a la fecha de la firma del contrato se aplicará al proyecto durante toda su vigencia a pesar de cualquier cambio posterior a la ley. Este aspecto implica que la legislación que entra en vigor después de la firma del contrato con el inversionista no se aplica al inversionista extranjero o al proyecto ${ }^{10}$.

Como es evidente, las cláusulas de congelación establecen una limitación más intensa a la soberanía del Estado, en contraste con los compromisos de no expropiar y con las cláusulas de equilibrio económico que veremos a continuación. Como ejemplo de cláusula de congelación, encontramos el siguiente contrato de América Latina estudiado en el Informe UN-IFC:

Specific Juridical Stability: The State guarantees the Investors and the Recipient Company that this Investment Contract, the Project Agreements and the State Institution Authorizations, in each case in relation to the Investments and the Project, shall enjoy absolute legal stability in accordance with the Legal Framework in Effect. Accordingly, neither the Investment Contract, nor the Project Agreements nor the State Institution Authorizations may be modified unilaterally by laws or other dispositions from the State of any type that affect them or by changes in the interpretation or application thereof and each thereof in which the State is a party may only be modified by the mutual written agreement of the Parties that expressly evidences such modifications (Shemberg, 2009, p. 6) [el énfasis es nuestro] ${ }^{11}$.

\section{Cláusulas de equilibrio económico}

Las cláusulas de equilibrio económico funcionan como cláusulas de indemnización que brindan equilibrio económico al contrato al garantizar que el inversionista tendrá a su disposición los recursos adecuados; si las acciones del Estado anfitrión afectan, de forma negativa, la economía subyacente del proyecto ${ }^{12}$.

Ahora bien, en virtud de este tipo de cláusulas, los cambios en la ley que se producen después de la celebración del contrato se aplican al proyecto y, por lo tanto, deben ser cumplidas por los inversionistas. Sin embargo, el gobierno anfitrión debe indemnizar a los inversionistas por los costos en que incurran, o los daños económicos que sufran como consecuencia de la nueva legislación. La compensación puede ser en forma de reembolsos, reajuste de tarifas, extensión del plazo de la concesión o reducciones de impuestos ${ }^{13}$.

clause," which comes in two versions. Under a rigid economic equilibrium clause, future changes in law would apply to the investor, but the host State would indemnify the investor for its compliance with the new legislation. Under a more flexible equilibrium clause, the host state and the investor would commit to conducting future negotiations with the goal of recalibrating the original allocation of risks or losses/gains, based on the reality of the new legislation (2011).

Asimismo, Ghene y Brillo han expresado que

it identifies three main types of modern stabilization practice. First, "freezing clauses" that exempt an investment from the application of new laws, "freezing" the law of the host state, either in its entirety or limited to certain regulatory fields (e.g. fiscal issues); second "equilibrium clauses" that cover the financial loss that relates to changes in law and third, "hybrid clauses" that are combinations of freezing and economic equilibrium clauses, providing in complementing each other "an additional layer of protection for stability of the contract". Hybrid clauses leave it to the parties to determine whether economic equilibrium is to be achieved through exemption from regulatory change or other forms of "alleviation of the unfavorable impact of changes" such as contract adaptation or compensation. The classification proposed by the study is a rough description of the characteristics of contract stabilization; it is not necessarily congruent with the terminology in practice $(2017$, p. 7$)$.

10 Existen también las consistency clauses. Bajo estas cláusulas, la legislación nacional del Estado anfitrión solo se aplica al proyecto si es consistente con el contrato de inversión.

11 "Estabilidad jurídica específica: El Estado le garantiza a los inversionistas y a la compañía recipiente que este contrato de inversión, los acuerdos del proyecto y las autorizaciones de la institución estatal, disfrutarán de absoluta estabilidad legal en concordancia con el marco legal en vigor en ese momento. Como tal, ni el contrato de inversión, ni los acuerdos del proyecto ni las autorizaciones de la institución estatal podrán ser modificadas unilateralmente por leyes u otras disposiciones estatales de cualquier tipo que las afecten, o por cambios en la interpretación o aplicación de este acuerdo o de otros donde el Estado sea parte, los cuales solo podrán ser modificados por un acuerdo escrito de las partes que evidencie expresamente dichas modificaciones" [traducción libre] [el énfasis es nuestro].

12 Este tipo de cláusula de estabilización requiere que cuando el Estado anfitrión promulgue alguna legislación o tome medidas administrativas que agraven los costos del proyecto, las partes consultarán para determinar las consecuencias económicas de dicho cambio o ajustarán automáticamente los términos del contrato; por su parte, el Estado anfitrión compensará al inversionista. Por lo tanto, estas cláusulas no restringen el alcance de la legislación posterior; sino que mitigan su impacto adverso en el inversionista.

13 Existe una tendencia creciente de las partes a favorecer las cláusulas de estabilización económica; es decir, cláusulas que aseguran que se puedan hacer ajustes y revisiones a un contrato si los derechos o intereses del inversionista extranjero se ven afectados negativamente por un cambio en las circunstancias. 
En otras palabras, a diferencia de las cláusulas de congelación, las cláusulas de equilibrio económico estabilizan el equilibrio económico del contrato en lugar del marco regulatorio en sí mismo. De tal forma, los cambios regulatorios son posibles siempre que se tomen medidas para restablecer el equilibrio económico de la inversión ${ }^{14}$. Como estas cláusulas se encuentran destinadas a preservar la economía del proyecto, el alcance de la obligación de indemnizar del Estado anfitrión depende de la fuerza negociadora de las partes y de la necesidad del Estado de la inversión propuesta ${ }^{15}$. Por ejemplo, el Estado anfitrión podría, eventualmente, imponer nuevas normas de emisiones con respecto a una planta de energía, sin embargo, los costos de modificar el diseño de la planta o de volver a instalarla serían de cargo del Estado ${ }^{16}$.

\section{B. Incidencia de los distintos tipos de cláusulas de estabilización en la práctica actual}

Como se ha indicado, los términos de las cláusulas de estabilización son relevantes para valorar su impacto en los derechos humanos y medioambientales. Por lo tanto, el análisis de sus tendencias actuales en América Latina es de vital importancia para determinar si respecto de ellas existen preocupaciones válidas.
Teniendo en cuenta la anterior descripción de sus tipos, en esta sección se analizará la frecuencia de las cláusulas de estabilización de acuerdo por tipos. El análisis de los posibles efectos de las cláusulas de estabilización que se dan en la práctica permite determinar si se limita la soberanía del Estado y, en caso afirmativo, si esos límites afectan áreas de importancia como, por ejemplo, el medioambiente, la salud o los derechos humanos.

El estudio más extenso sobre el contenido y el efecto de las cláusulas de estabilización fue realizado por la ONU y la CFI en el año $2009^{17}$. Sin embargo, en términos generales, la recopilación de datos relacionados con el contenido de este tipo de acuerdos es difícil de efectuar; debido a la naturaleza confidencial de estos contratos (Shemberg, 2009, p. viii).

Ahora, en el cuadro que figura a continuación, se muestra la incidencia de las tres categorías principales de cláusulas de estabilización en América Latina (ver gráfico).

Este aspecto contrasta con la realidad de las cláusulas de estabilización en el contexto mundial. Ahora bien, como se muestra en el cuadro que figura a continuación, estas disposiciones son espe-

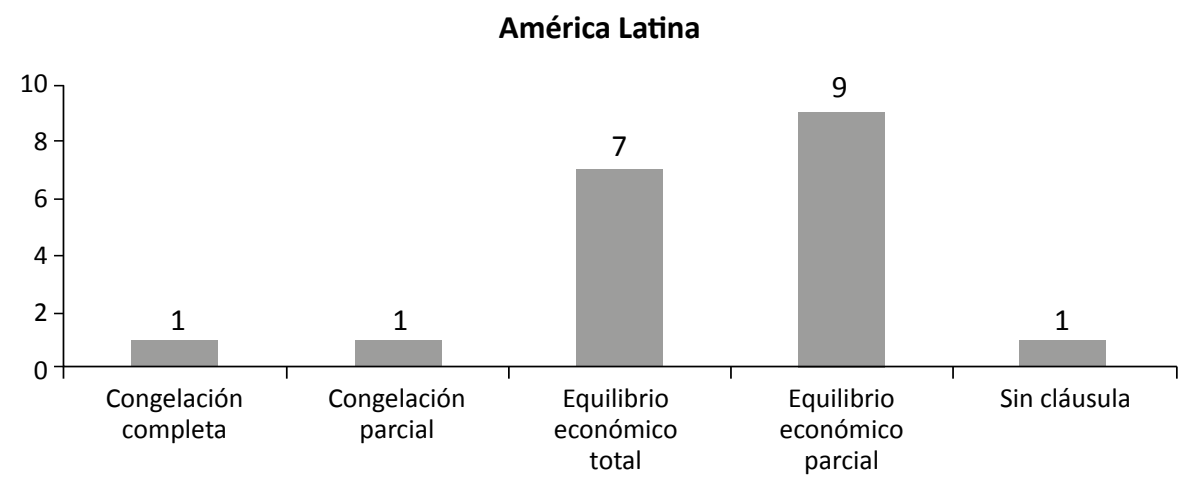

Elaboración propia a partir de la información brindada por Shemberg (2009, p. 19).

14 Las cláusulas de equilibrio económico también pueden facultar a los árbitros para determinar ajustes al contrato si las negociaciones fracasan.

15 Las cláusulas de estabilización vienen en todas las formas imaginables. Las cláusulas de estabilización más antiguas obligaban al Estado anfitrión a no nacionalizar y exigían el consentimiento de ambas partes contratantes para realizar modificaciones al contrato ("cláusulas de intangibilidad"). Las cláusulas de estabilización más recientes se han convertido en herramientas diversas y sofisticadas para gestionar el riesgo no comercial asociado al proyecto de inversión. Su alcance ha tendido a ampliarse, a efectos de incluir cambios en el marco regulatorio como la estabilización de aspectos específicos del proyecto de inversión, como su régimen fiscal o su estructura tarifaria.

16 Las cláusulas de equilibrio económico figuran, por ejemplo, en el production sharing agreement entre AGIP/British Petroleum/Etal - Kashagan Production - Sharing Company de 1997 y en los acuerdos contractuales para el Gasoducto de África Occidental (WAGP)

17 Para mayor información, véase a Shemberg (2009). 


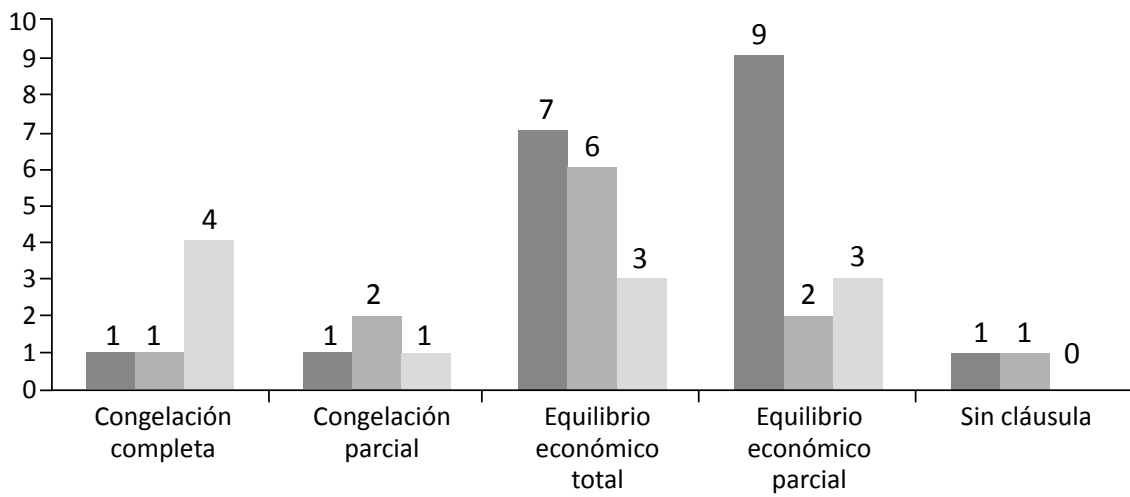

- América Latina

- Norte de África Oriente Medio

África

Subsahariana

Elaboración propia a partir de la información brindada por Shemberg (2009, p. 19).

cialmente preocupantes en regiones como África y el Medio Oriente (ver gráfico).

Como se muestra, las cifras analizadas por la CFI en su estudio y sus conclusiones varían cuando sólo se considera la región de América Latina. Si bien algunas de las cifras mostradas por la CFI llevan a la conclusión de que las cláusulas de estabilización son perjudiciales para los derechos humanos y el interés público, estas conclusiones dependen -en gran medida- del contenido de los contratos de inversión en África y el Medio Oriente (Shemberg, 2009, p. 19). De hecho, la región de América Latina y el Caribe muestra la prevalencia de cláusulas contractuales que equilibran los intereses de los Estados y los inversionistas de manera más eficiente. En ese sentido, algunos hechos interesantes son:

a) En América Latina y el Caribe, los contratos con cláusulas de estabilización ascienden a un $94,7 \%$ (Shemberg, 2009, p. 19).

b) Solamente uno de los contratos estudiados en América Latina y el Caribe incluye una cláusula de congelación. Este contrato está relacionado con el sector del transporte y no se limita a medidas fiscales o económicas (en particular, dicho contrato cubre los cambios en las leyes laborales) (Shemberg, 2009, p. 19).

c) El $47,1 \%$ de las cláusulas de equilibrio económico estudiadas son cláusulas de equilibrio "completo", puesto que tienen efectos sobre todo el marco regulatorio y no se limitan a medidas fiscales. El 52,9 \% restante contiene cláusulas de equilibrio limitadas; es decir, sólo limitan los cambios en la regulación relacionados con impuestos (Shemberg, 2009, p. 19).

Como se puede observar, en los últimos años, el uso de cláusulas de equilibrio económico se ha visto sustancialmente incrementado en contraste con las cláusulas de congelación. Como es de esperar, la razón de su creciente popularidad es su mayor flexibilidad y versatilidad ${ }^{18}$.

De tal forma, la situación actual de las cláusulas de estabilización en la región de América Latina muestra que, por lo general, estas cláusulas no tienen un impacto excesivo sobre la capacidad de los Estados para regular sobre el interés público. Todo este aspecto se tiene en cuenta tanto el ámbito del derecho sobre el que tienen efectos (generalmente medidas fiscales-económicas) como su efecto previsto: equilibrar los aspectos económicos del contrato en lugar de congelar la regulación.

\section{EFECTOS DE LAS CLÁUSULAS DE ESTABILIZA- CIÓN}

A. Validez de las cláusulas de estabilización según la jurisprudencia

Los contratos de inversión en general y las cláusulas de estabilización en particular, han sido objeto de reclamaciones de inversionistas extranjeros

18 Es importante mencionar que el profesor Umirdinov ha resaltado que existen tres tipos de cláusulas de estabilización: [s]tipulated Economic Balancing (“SEB"), Non-specified Economic Balancing ("NSEB"), and Negotiated Economic Balancing ("NEB"). The SEB instructs the automatic amendment of the contract in a predetermined fashion; NSEB does not specify the nature of an automatic amendment, neither does it necessitate the mutual agreement of the parties. In the case of NEB, parties are also under an obligation to meet so that they may make necessary amendments to the agreement (2015, p. 466). 
basadas en diferentes disposiciones de tratados de inversión. La cuestión de la validez y la aplicabilidad de las cláusulas de estabilización se trató en casos decididos entre los años 1980 y 1990 en los cuales se afirmó su validez ${ }^{19}$

Este último aspecto es una consecuencia lógica del hecho de que el Estado es libre de decidir si firma contratos con este tipo de cláusulas. Sin embargo, como se examinará en la siguiente sección, dicha conclusión no impide el debate sobre la medida en que el Estado puede limitar su soberanía en el cumplimiento de otras obligaciones de derecho internacional. Al respecto, en el caso AGIP Co. SpA c. República Popular del Congo, el tribunal arbitral señaló lo siguiente:

Stabilization clauses, freely accepted by the Government, do not affect the principle of its sovereign legislative and regulatory powers, since it retains both in relation to those, whether national or foreigners, with whom it has not entered into such obligations [...] changes in the legislative and regulatory agreements stipulated in the agreement simply cannot be invoked against the other contracting party $(1979 \text {, párr. } 86)^{20}$.

\section{B. Efectos en la actuación estatal derivados de la existencia de una cláusula de estabiliza- ción con un inversionista}

1. La regulación selectiva, la no aplicación de la regulación al inversionista y las indemnizaciones por daños y perjuicios

Como hemos señalado desde el principio, el objetivo de una cláusula de estabilización es ofrecer a los inversionistas, y a sus prestamistas, cierta seguridad de que la inversión no estará sujeta a cambios impredecibles y costosos en la ley. En otras palabras, la función de estas cláusulas es garantizar que el marco regulatorio aplicable al contrato no se altere y permanezca "estabilizado" 21 .

No obstante, las cláusulas de estabilización, en principio, no prohíben a un Estado promulgar nueva legislación; sino que impiden que entren en vigor nuevas regulaciones en desmedro del inversionista. En ese sentido, el profesor Peter ha señalado que el efecto de las cláusulas de estabilización, de forma independiente de su naturaleza, es la siguiente:

To preclude the application to an agreement of any subsequent legislative (statutory) or administrative (regulatory) act issued by the government or the administration that modifies the legal situation of the investor (1995, p. 214) 22 .

En esta misma línea, algunas voces críticas han identificado aspectos de actuación estatal que podrían ser perjudiciales para la consecución de objetivos relacionados con el desarrollo sostenible, los derechos humanos y la conservación del medioambiente. En ambos casos, los Estados realizan los cambios reglamentarios necesarios. No obstante, o bien diseñan esos cambios para evitar su aplicación a las inversiones en curso, o bien no los aplican a los inversionistas con los que han celebrado contratos de inversión que contienen cláusulas de estabilización (Cotula, 2008, p. 3).

Por otra parte, algunos sectores de la doctrina van más allá de esta interpretación y señalan que el efecto de las cláusulas de estabilización será siempre el pago de una indemnización por daños y perjuicios. Sobre el particular, los profesores Ghene y Brillo han señalado que

stabilization clauses do not actually prevent governments from regulating; even freezing clauses do not exclude a host government's

19 Por ejemplo, en el caso de AGIP Co. SpA c. República Popular del Congo, el tribunal arbitral determinó que las cláusulas de estabilización eran parte del derecho internacional. Por su parte, en el caso LETCO c. Liberia (1996), se señaló que tales cláusulas eran obligatorias y, por ende, debían ser respetadas. De forma reciente, en el caso CMS c. Argentina (2005), el tribunal arbitral señala que las cláusulas de estabilización son reconocidas en el derecho internacional y, por ello, podían ser invocadas por los inversionistas. Un ejemplo en que se analizó la validez de las cláusulas de estabilización es el caso Duke Energy c. Perú. En relación a este caso, Nathanson señaló que

[o]ne example of a stabilization clause operating to protect investors is Duke Energy. Duke Energy International ("DEI") and Peru signed a "Legal Stability Agreement" ("LSA") through which DEI would be protected from changes in law, such as laws of the tax system. Peru agreed to this and other LSAs because the country was undergoing extensive privatization during the 1990s, and it wished to attract FDI in electricity and gas. While the LSA was for a period of ten years, Peru imposed a contrary additional tax assessment on DEI prior to the LSA's termination date, and the International Centre for Settlement of Investment Disputes ("ICSID") tribunal found that Peru had breached the LSA (2012, p. 879)

20 "Las cláusulas de estabilización libremente aceptadas por el gobierno no afectan la soberanía de sus poderes legislativos y regulatorios, ya que el Estado la mantiene al relacionarse con los particulares, sean nacionales o extranjeros, con quienes no ha contraído dichas obligaciones [...] así, los cambios en los acuerdos legislativos y regulatorios estipulados en el acuerdo principal simplemente no pueden ser invocados en contra de la otra contratante" [traducción libre].

21 Por ejemplo, el cambio podría encontrarse relacionado con el nivel de impuestos aplicable a un proyecto.

22 "Imposibilita que se le aplique a un acuerdo cualquier ley (estatuto) o regulación administrativa emitida subsiguientemente por el gobierno o la administración que modifique la situación legal del inversionista" [traducción libre] 
exercise of power in the public interest. The key consequence of stabilization clauses is that changes in law come with a price to pay $(2017$, p. 14$)^{2324}$.

De hecho, incluso en el caso de que surja una disputa entre inversionista y Estado, el efecto más probable de un incumplimiento de las cláusulas de estabilización es el otorgamiento de una indemnización por daños y perjuicios ${ }^{25}$. El cumplimiento específico sigue siendo un recurso escaso y casi inexistente para las violaciones del derecho internacional por parte de los Estados ${ }^{26}$. Este aspecto determina que el efecto de las cláusulas de congelación y de las cláusulas de equilibrio económico acabe siendo el mismo.

Con respecto al efecto indemnizatorio, un dato a tener en cuenta es que incluso las cláusulas de estabilización más laxas pueden obligar a un Estado anfitrión a compensar a un inversionista (incluso cuando las modificaciones regulatorias no serían indemnizables bajo el Derecho Internacional Público). De esta manera, incluso si un inversionista no pudiese reclamar el pago de una indemnización bajo el estándar de "privación sustancial" de la expropiación o bajo las legítimas expectativas del inversionista bajo el estándar del trato justo y equitativo, ese mismo inversionista podría solicitar la indemnización por el incumplimiento de la cláusula de estabilización por parte del Estado anfitrión ${ }^{27}$.

\section{El regulatory chill o la abstención de los esta- dos de regular en el interés público}

Otro de los posibles efectos perjudiciales de las cláusulas de estabilización en relación con el espacio normativo de los Estados es el denominado regulatory chill. Este último concepto abarca, de forma esencial, las situaciones en las que el Esta- do se abstiene de realizar cambios en la regulación para evitar las consecuencias negativas derivadas de los supuestos incumplimientos de sus obligaciones con los inversionistas extranjeros ${ }^{28}$.

El regulatory chill ha sido objeto de opinión y análisis académico en diferentes trabajos en los que se analizan doctrinas como los regulatory takings, o las expectativas legítimas de estabilidad regulatoria bajo el estándar del trato justo y equitativo (Ghene \& Brillo, 2017, p. 15). Sin embargo, la existencia de este efecto todavía no es una cuestión pacífica. Algunas líneas de opinión sugieren que el regulatory chill no acontece en la práctica, y que la actividad soberana no se ve limitada por las posibles responsabilidades con respecto al inversionista (Ghene \& Brillo, 2017, p. 15).

Por otra parte, se cree que la probabilidad de enfrentar costosos procedimientos internacionales $y$, en última instancia, significativos daños al inversionista, son tenidos en cuenta por los Estados al decidir si realizan los cambios reglamentarios necesarios (Ghene \& Brillo, 2017, p. 15). Sin embargo, los datos no son concluyentes en lo que corresponde a los aspectos más generales de la legislación sobre inversiones (como el trato justo y equitativo), y casi no existen en el ámbito de la actuación estatal con respecto a cláusulas de estabilización ${ }^{29}$.

\section{Efectos para el Estado derivados del incum- plimiento de los tratados de arbitraje de in- versión firmados por el Estado}

En términos generales, la presencia de una cláusula de estabilización ha sido un factor determinante a la hora de decidir si se violaron los derechos de los inversionistas en virtud de los tratados internacionales de inversión. No obstante, este aspecto tiene distintos efectos en caso de que se valore el

23 "[L]as cláusulas de estabilización en realidad no evitan que los gobiernos regulen; incluso las cláusulas de congelamiento no privan al gobierno anfitrión de su ejercicio del poder a favor del interés público. La consecuencia clave de las cláusulas de estabilización es que los cambios a la ley ahora vienen con un precio a pagar" [traducción libre]

24 En el mismo sentido, Nathanson ha expresado que las cláusulas de estabilización "do not necessarily represent the relinquishment of sovereign powers - according to one tribunal, through a stabilization clause, a State '[does] not alienate but exercises its sovereignty'” (2012, p. 878-879).

25 Para mayor información, véase a Schreurer (2004) y a Sinclair y Triantafilou (2017).

26 Aun así, las órdenes de cumplimiento específico no son completamente ajenas al derecho internacional. Por ejemplo, recientemente en Goetz c. Burundi (1999) y Arif c. Moldavia (2013), se analizó la problemática derivada de las órdenes de cumplimiento específico en casos en los que una parte es un estado. En ambos se dio esta orden dándola como alternativa al pago de una indemnización de daños a discreción del Estado. Asimismo, en Grenada Private Power Ltd. y WRB Enterprises c. Granada (2020), un tribunal arbitral ordenó al Estado la compra de las acciones de un proveedor de energía local por encima del precio de mercado.

27 Para mayor información, véase a Nelson (2011)

28 Para mayor información, véase a Cotula (2008) y a Ghene y Brillo (2017).

29 Como se menciona, el Representante Especial del Secretario General de la ONU y la Corporación Financiera Internacional llevaron a cabo un Proyecto de investigación centrado en los contratos entre estados e inversionistas y, en particular, sobre las cláusulas de estabilización y su impacto en los derechos humanos. 
incumplimiento de la prohibición de la expropiación sin compensación, y el del estándar de trato justo y equitativo. Además, no se ha dictado ningún fallo en relación con la variedad más moderna de cláusulas de equilibrio económico; esto es, las que prevén negociaciones obligatorias.

1. Cláusulas de estabilización y la prohibición de expropiación ilegal

En general, los tribunales no han determinado que se ha producido una expropiación indirecta o progresiva por parte del Estado al incumplir una cláusula de estabilización (Cotula, 2008, p. 5). Por ejemplo, en Burlington c. Ecuador (2017), el tribunal señaló que los cambios en la regulación fiscal no constituían una expropiación de la inversión incluso en presencia de una cláusula de estabilización económica a favor del inversionista ${ }^{30}$.

Por otra parte, desde un punto de vista teórico, incluso los derechos derivados de los contratos pueden equivaler a inversiones. En ese sentido, la aplicación de nueva legislación por parte de los Estados anfitriones a una inversión cubierta por una cláusula de estabilización podría ser vista como una especie de expropiación, bajo el entendido de que no se puede estar sujeto a dicha nueva legislación sin compensación. No obstante, este aspecto no ha sido analizado por ningún laudo arbitral hasta la fecha.

2. Cláusulas de estabilización y el estándar de trato justo y equitativo

En relación con el estándar del trato justo y equitativo, la mayor incidencia que las cláusulas de estabilización han tenido en la jurisprudencia se encuentra relacionada a las expectativas legítimas del inversionista. Cabe indicar que, en la medida que el incumplimiento de una cláusula de estabilización siempre se encuentra ligado a cambios normativos, esta actividad estatal no se encuentra siempre proscrita a los Estados en ejercicio de su soberanía. En ese sentido, algunos comentaristas han señalado, de forma asertiva, que los inversionistas responsables no "esperarán legítimamente" que el Estado no adopte una reglamentación de buena fe, especialmente en lo que respecta a las normas ambientales y de derechos humanos ${ }^{31}$.
En esta línea de criterio, distintos tribunales arbitrales han señalado que no se puede encontrar, dentro de las expectativas legítimas del inversionista, el asumir que el marco regulatorio permanecerá inalterado durante toda la vida de la inversión. Por ejemplo, en Feldman c. México el tribunal arbitral señaló lo siguiente:

[g]overnments must be free to act in the broader public interest through protection of the environment, new or modified tax regimes, the granting or withdrawal of government subsidies, reductions or increases in tariff levels, imposition of zoning restrictions and the like. Reasonable government regulation of this type cannot be achieved if any business that is adversely affected may seek compensation, and it is safe to say that customary international law recognizes this (2002, párr. 103) [el énfasis es nuestro] ${ }^{32}$.

Asimismo, en el caso Eiser Infrastructure c. España, el tribunal arbitral concluyó lo siguiente:

En ausencia de compromisos explícitos directamente extendidos a los inversores y que garanticen que los Estados no modificarán sus leyes y reglamentos, los tratados en materia de inversiones no eliminan el derecho de los Estados a modificar sus regímenes regulatorios para adaptarse a circunstancias y necesidades públicas cambiantes. Tal como advirtieran otros tribunales, "[a] fin de adaptarse a las circunstancias económicas, políticas y legales cambiantes, las facultades regulatorias del Estado se mantienen en su lugar". [...] [E]l estándar de trato justo y equitativo no otorga un derecho de estabilidad regulatoria per se. El estado tiene un derecho a regular, y los inversores deben esperar que la legislación cambiará, si no existe una cláusula de estabilización u otra garantía específica que genere una expectativa legítima de estabilidad (2017, párr. 362) [el énfasis es nuestro].

De igual manera, en AES Summit Generation Limited and AES-Tisza Erömü Kft c. Hungría, el tribunal arbitral sostuvo que "[a] legal framework is by definition subject to change as it adapts to new circumstances day by day and a state has the sovereign right to exercise its powers which include

30 Para mayor información, véase el caso Burlington Resources Inc. c. Ecuador (2017).

31 Para mayor información, véase a Sheppard y Crockett (2011).

32 "Los gobiernos deben ser libres de actuar a favor del interés público generalizado a través de la protección del medio ambiente, nuevos o modificados regímenes tributarios, la concesión o retiro de subsidios, reducciones o incrementos en los niveles de las tarifas, la imposición de restricciones zonales y otras medidas. Este tipo de regulación gubernamental razonable no puede ser alcanzada si cualquier negocio que se ve adversamente afectado puede pedir compensación, y el derecho internacional consuetudinario reconoce esto" [traducción libre]. 
legislative acts" (2010, párr. 9.3.29) [el énfasis es nuestro].

Sin embargo, en los casos en los que el Estado había firmado una cláusula de estabilización con el inversionista, los tribunales han considerado que este último sí podía esperar legítimamente que el marco regulatorio no cambiaría. Por ejemplo, en Total c. Argentina, el tribunal señaló lo siguiente:

[t]he expectation of the investor is undoubtedly "legitimate", and hence subject to protection under the fair and equitable treatment clause, if the host State has explicitly assumed a specific legal obligation for the future, such as by contracts, concessions or stabilization clauses on which the investor is therefore entitled to rely as a matter of law (2010, párr. 117) [el énfasis es nuestro] ${ }^{33}$.

Otra línea de casos, que logra mostrar el valor de las cláusulas de estabilización, son aquellos en los que la falta de tal compromiso con el Estado ha sido parte de la ratio decidendi para afirmar la capacidad del Estado consistente en cambiar el marco normativo. En ese mismo sentido, en el caso Parkerings c. Lituania señala lo siguiente:

It is each State's undeniable right and privilege to exercise its sovereign legislative power. A State has the right to enact, modify or cancel a law at its own discretion. Save for the existence of an agreement, in the form of a stabilization clause or otherwise, there is nothing objectionable about the amendment brought to the regulatory framework existing at the time an investor made its investment. As a matter of fact, any businessman or investor knows that laws will evolve over time. What is prohibited however is for a State to act unfairly, unreasonably or inequitably in the exercise of its legislative power (2010, párr. 332) [el énfasis es nuestro] ${ }^{34}$.

Esta misma línea de razonamiento fue adoptada en el reciente caso Anglo American PLC c. Venezuela. Como se puede observar, las cláusulas de estabilización se han analizado sobre todo al evaluar las expectativas legítimas de los inversionistas en el marco de la norma de trato justo y equitativo, adquiriendo una mayor importancia en los casos en que el Estado no concedió una cláusula de estabilización al inversionista.

\section{CRÍTICAS A LAS CLÁUSULAS DE ESTABILIZA- CIÓN EN EL CONTEXTO DE LA REFORMA DE LA SOLUCIÓN DE CONTROVERSIAS ENTRE INVERSIONISTAS Y ESTADOS}

Como consecuencia de la liberalización del comercio y la inversión a nivel internacional, muchos países en vía de desarrollo se encuentran poniendo todos sus esfuerzos en captar inversión extranjera. Estos esfuerzos, en muchos casos, están centrados en garantizar al inversionista que su inversión se desarrollará en un marco jurídico estable (como las cláusulas de estabilización). Sin embargo, este tipo de mecanismos de garantía están cada vez más expuestos a un riguroso escrutinio por parte de la comunidad internacional, la cual critica con vehemencia los casos en que las inversiones socavan el desarrollo sostenible, la realización de los derechos humanos y la sostenibilidad ambiental.

De tal forma, a pesar de que las cláusulas de estabilización son beneficiosas para los inversionistas extranjeros y son percibidas como una ayuda para los Estados anfitriones para captar inversiones extranjeras, reducen el espacio regulatorio del Estado. Este aspecto puede evitar, al mismo tiempo, que los Estados anfitriones tomen las medidas necesarias en ámbitos de interés público como proteger los derechos de sus ciudadanos y el medioambiente, y hacer cumplir las leyes nacionales ${ }^{35}$. Sobre el particular, el profesor Gjuzi ha señalado que

[t]he scope of regulatory risk, as perceived by foreign investors and as addressed by means of stabilization clauses, may overlap and even contradict the scope of the host state's sovereign right and duty to regulate in the evolving areas of public interest, including those of environmental protection and human rights. In view of this, the stabilization clause has the potential to generate a conflict between, on the one hand, the host state's promise for main-

"La expectativa del inversionista es indudablemente "legitima", y por ello, está sujeta a ser protegida bajo la cláusula del trato justo y equitativo, si el Estado anfitrión ha asumido explícitamente una obligación legal específica para el futuro, como por ejemplo, por contratos, concesiones o cláusulas de estabilización por las cuales el inversionista en las que tiene la facultad legal de depender" [el énfasis es nuestro] [traducción libre].

34 "El ejercicio soberano del poder legislativo es el derecho y privilegio innegable de cada Estado. Un Estado tiene derecho a promulgar, modificar o derogar una ley según su propia discreción. Salvo por la existencia de un acuerdo, en la forma de una cláusula de estabilización o de otra manera, no hay nada objetable respecto de una enmienda hecha al marco regulatorio vigente al momento en el que se hizo la inversión. De hecho, cualquier empresario o inversionista sabe que las leyes evolucionarán en el tiempo. Lo que está prohibido, sin embargo, es que un Estado actué de manera injusta, irrazonable o inequitativa en el ejercicio de su poder legislativo" [el énfasis es nuestro] [traducción libre].

35 Para mayor información, véase a Crockett (2011) y a Cotula (2018). 
taining the investment regime stable and unaffected by subsequent regulatory changes in areas of public interest, and on the other hand, the host state's need to regulate in such areas. Obviously, this is the case where the technique and scope of stabilization clauses covers these areas of state interference (the so-called 'broad stabilization clauses') $(2018, \text { p. } 3)^{36}$.

Es precisamente por esta razón que varias voces han denunciado que las cláusulas de estabilización limitan la capacidad del Estado soberano de cumplir con sus obligaciones internacionales de derechos humanos ${ }^{37}$. Por ejemplo, la organización internacional de derechos humanos Amnistía Internacional ha criticado, de forma enfática, las cláusulas de estabilización por poner un precio a los derechos humanos ${ }^{38}$.

Sin embargo, como se ha apuntado de forma anterior, el verdadero efecto que estas cláusulas tendrán sobre el espacio regulatorio del Estado en el interés público depende de los términos de cada cláusula particular. Como se ha podido observar, la tendencia actual en América Latina no tiene mucha incidencia sobre la capacidad regulatoria del Estado, puesto que las cláusulas prevalentes son de equilibrio económico y dentro de estas últimas la mayoría solo son aplicables a cambios en la regulación fiscal.

A pesar de ello, las críticas siguen persistiendo. De hecho, se considera que incluso las cláusulas de equilibrio económico constituyen un elemento regulador disuasorio para el Estado, puesto que los cambios en el marco regulatorio (incluso en normas ambientales y sociales) llevan a que aquel se enfrente a tener que renegociar el equilibrio económico del contrato (Crockett, 2011, p. 516). Este último aspecto resulta particularmente pertinente en los sectores de la energía y los recursos naturales, en los que las inversiones pueden ser económicamente sensibles a dichas modificaciones $(2011, \text { p. } 516)^{39}$.
Otros comentaristas, por su parte, van más allá, al considerar que las limitaciones a la política fiscal repercuten en las esferas de la reglamentación en el interés público ${ }^{40}$. En esta línea de opinión, algunos sectores de la doctrina tienen en cuenta los efectos de las políticas fiscales en ciertos aspectos sociales y ambientales (como la redistribución de la riqueza o la internalización de los costos ecológicos) y, por ello, argumenta en contra de la limitación del espacio regulatorio también en las esferas fiscal y económica (Frank, 2014, p 197).

Uno de los ejemplos paradigmáticos en que se puede apreciar la relación de tensión entre las cláusulas de estabilización y el interés público se refiere a los casos de los peajes en el Perú. El Estado peruano celebró con diversos inversionistas contratos de concesión que se estabilizaron mediante contratos de seguridades y garantías ${ }^{41}$. Como consecuencia de ello, el régimen legal quedó estabilizado en favor de cada una de las concesionarias.

Sin embargo, a raíz de la pandemia ocasionada por la COVID-19, el 7 de mayo del 2020, el Congreso peruano promulgó por insistencia la Ley 31018, Ley que suspende el cobro de peajes en la red vial nacional, departamental y local concesionada durante el Estado de Emergencia Nacional (en adelante, Ley que Suspende el Cobro de Peajes). Dicha norma menciona siguiente:

\section{Artículo único. Suspensión del cobro de peaje}

Suspéndase con carácter excepcional y provisional del cobro de peaje en todas las unidades de peaje de la red vial nacional, departamental y local concesionada, con el objeto de evitar el contacto con los usuarios y cumplir con el aislamiento obligatorio mientras dure el estado de emergencia nacional dispuesto por el Poder Ejecutivo ante los riesgos de propagación del COVID-19.

La suspensión establecida en el presente artículo no causará ni generará derecho compensatorio.

36 "El alcance del riesgo regulatorio, de la forma en la que es percibido por los inversionistas extranjeros y abordado por las cláusulas de estabilización, puede abarcar e incluso contradecir el alcance del derecho soberano y deber del Estado anfitrión de regular en las evolutivas áreas de interés público, que incluyen la protección del medio ambiente y los derechos humanos. En atención a ello, la cláusula de estabilización tiene el potencial de generar conflicto entre, por un lado, la promesa del Estado anfitrión de mantener el régimen de inversión estable e inafectado por subsecuentes cambios en la regulación en áreas de interés público; y por otro, la necesidad del Estado anfitrión de regular en estas áreas. Obviamente, este es el caso cuando la técnica y el alcance de las cláusulas de estabilización cubre esas áreas de intervención estatal (las llamadas cláusulas de estabilización amplias)" [traducción libre].

37 Para mayor información, véase a Sheppard y Crockett (2011).

38 Para mayor información, véase Amnistía Internacional (2006).

39 Para mayor información, véase a Sheppard y Crockett (2011).

40 Para mayor información, véase a Cotula (2018) y a Frank (2014).

41 El Estado peruano otorgó seguridades y garantías a las concesionarias de la red vial nacional, mediante los siguientes Decretos Supremos: (i) Decreto Supremo 008-2020-EF; (ii) Decreto Supremo 192-2010-EF; (iii) Decreto Supremo 1802009-EF; (iv) Decreto Supremo 037-2009-EF; (v) Decreto Supremo 124-2005-EF; y, (vi) Decreto Supremo 177-2002-EF. 
Como es evidente, es perfectamente posible argumentar que la promulgación de la Ley que Suspende el Cobro de Peajes respondía a la tutela del interés público y a la protección de los derechos humanos. De tal forma, el Congreso podría argumentar que la promulgación de la ley era necesaria para proteger los legítimos objetivos de bienestar público como la salud y la seguridad de la población.

Sin embargo, no nos cabe la menor duda de que, con la promulgación de la Ley que Suspende el Cobro de Peajes, se han violado los contratos de concesión y los contratos de seguridades y garantías celebrados por las concesionarias y el Estado peruano. La propia naturaleza de las cláusulas de estabilización determina que el este no puede cambiarle las reglas de juego a las concesionarias. En efecto, estas últimas invirtieron bajo la representación -contenido en los contratos de seguridades y garantías- de que iban a poder cobrar un peaje. De tal forma, los contratos de concesión se encontraban blindados frente a futuros cambios legislativos.

En ese sentido, en el caso Europe Investments Limited c. República Checa, el tribunal arbitral concluyó lo siguiente:

Having carefully considered all materials before it, the Tribunal agrees with the Respondent that it did not expressly undertake any agreed stabilization commitment, be it contractual, legislative, individual or otherwise, vis-à-vis the Claimant's investment. Had the Tribunal found that such stabilization commitment existed in the present circumstances, there would obviously have been a solid basis to allege that changes in the law applicable to the foreign investment in question were unlawful (2019, párr. 396) ${ }^{42}$.

Como consecuencia de ello, más allá de que haya existido la necesidad legítima de suspender el cobro de los peajes en virtud del interés público y la protección de los derechos humanos, lo cierto es que dicho estado se encontraba imposibilitado de hacerlo sin incurrir en responsabilidad. En efecto, las cláusulas de estabilización previstas en los contratos de seguridades y garantías así lo determinaban. Interpretar que sí se encontraba habilitado para suspender el cobro de peajes implica despojar de funcionalidad y de sentido a los contratos de estabilización.

Este último aspecto es uno de los típicos casos en que se puede apreciar la relación tóxica existente entre las cláusulas de estabilización y el interés público. En efecto, si bien es verdad que las cláusulas de estabilización pueden ser muy virtuosas para atraer inversión extranjera, no existe la menor duda de que restringen la soberanía del Estado para legislar en virtud del interés público.

\section{A. Nuevas tendencias en la negociación y re- dacción de cláusulas de estabilización en América Latina}

Todas las críticas reflejan el contenido y la manera de negociar este tipo de cláusulas que, como se ha demostrado, son en ocasiones necesarias. Ahora bien, dos de las tendencias más prometedoras en el sector (de forma específica, en América Latina) son la participación de las comunidades afectadas por las inversiones en la negociación del contrato y la inclusión de excepciones a la aplicación de las cláusulas en áreas de interés público.

1. La participación de las comunidades afectadas en la negociación del contrato

Un aspecto que tiene gran incidencia en las relaciones entre inversionistas y Estados en América Latina es la obligación de brindar a las comunidades indígenas una consulta previa libre e informada sobre los proyectos que les afecten. Dicha obligación se encuentra basada en el Convenio 169 de la Organización Mundial del Trabajo ${ }^{43}$ y algunas normas internas de los Estados que desarrollan lo dispuesto en esta norma internacional ${ }^{44}$.

En este contexto, distintos instrumentos de soft law señalan que los contratos entre inversionistas y Estados también deberían encontrarse sujetos a una consulta previa. Por ejemplo, el principio 7 de los Principios sobre Contratos Responsables de las Naciones Unidas señala que será necesario involucrar a las comunidades afectadas desde los inicios de la negociación del contrato ${ }^{45}$. Otro ejemplo son

42 "Habiendo considerado cuidadosamente todos los materiales ante este, el Tribunal concuerda con el Demandado que este último no se comprometió a ninguna cláusula de estabilización acordada, sea contractual, legislativa, individual u otra, vis-à-vis la inversión del Demandante. Si el Tribunal hubiese encontrado que un compromiso de estabilización tal existiese en las presentes circunstancias, obviamente habría habido una base sólida para alegar que los cambios de la ley aplicable a la inversión extranjera en cuestión fueron ilegales" [traducción libre].

43 Para mayor información, véase Convenio 169 de la Organización Mundial del Trabajo, de 27 de junio de 1989.

44 Como, por ejemplo, la Ley 29785, Ley del derecho a la consulta previa a los pueblos indígenas u originarios, reconocido en el Convenio 169 de la Organización Internacional del Trabajo.

45 Para mayor información, véase el documento Principios de Contratación Responsable: Integración de la Gestión de los Riesgos Relacionados con los Derechos Humanos en las Negociaciones entre Estados e Inversiones (Oficina del Alto Comisionado de los Derechos Humanos de las Naciones Unidas, 2015). 
las directrices voluntarias de la USAID sobre inversiones basadas en terrenos, las cuales señalan lo siguiente: "include in negotiations those who use or claim the land [...], even if their rights are not formally recognized" (Boudreaux \& Neyman, 2015, p. 37)

Pese a la tendencia que se puede observar en estos instrumentos de soft law, hasta la fecha no se ha regulado en ningún instrumento la obligación de incluir a estas comunidades en las negociaciones del contrato. Sin embargo, los derechos de las comunidades indígenas se encuentran teniendo gran incidencia en el derecho internacional de inversiones, tal y como se demuestra por el reciente aumento de laudos de arbitraje de inversión en que los derechos de los inversionistas se han visto afectados por acciones del Estado tendentes a respetar los derechos de estas comunidades ${ }^{46}$. Por ello, dicha tendencia podría materializarse en esfuerzos por parte de los Estados para incluir los intereses de estas comunidades incluso antes del inicio de la inversión (por ejemplo, durante la negociación de los contratos). Este tipo de iniciativas podría tener un impacto positivo sobre el contenido de las cláusulas de estabilización y la protección de los derechos humanos y el medioambiente.

2. La inclusión de excepciones aplicables a ciertos ámbitos como el medio ambiente o los derechos humanos

Por otra parte, una tendencia reciente que ha surgido en los contratos de inversión es la separación de ciertas esferas de la regulación (generalmente, en materia ambiental y social) de los efectos de las cláusulas de estabilización y la inclusión de obligaciones para los inversionistas en esas mismas esferas. Este aspecto garantiza al Estado que conservará su capacidad de regular en aras del interés público, a la vez que le brinda la posibilidad de responsabilizar al inversionista en aquellos casos en que no cumpla las leyes ambientales, sociales o de seguridad.

Un ejemplo paradigmático de una cláusula de este tipo en la región de América Latina y el Caribe es el contrato modelo de Trinidad y Tobago para inversionistas en el sector petrolífero. La cláusula prevé la posibilidad de que las normas ambientales aplicables cambien (normas ambientales aplicables en cada momento) y obliga al inversionista a cumplir con cualquiera de estos cambios. En ese sentido, Cameron indica lo siguiente:
El Contratista llevará a cabo las Operaciones Petroleras en virtud del presente documento de manera continua, diligente y profesional, de conformidad con las leyes aplicables y el Contrato, y las prácticas internacionales sólidas y actuales de la industria petrolera y las normas ambientales aplicables en cada momento en circunstancias similares, todo ello con el fin de lograr una Exploración y Producción de Petróleo eficiente y segura y maximizar la recuperación final de Petróleo del Área de Contrato (2006, p. 78).

\section{LA APLICABILIDAD Y VALIDEZ DE LAS CLÁU- SULAS DE ESTABILIZACIÓN EN CASOS DE CONFLICTO CON LAS OBLIGACIONES DE DE- RECHOS HUMANOS}

Como se ha podido observar de forma anterior, las cláusulas de estabilización han sido objeto de numerosos laudos arbitrales. No obstante, hasta la fecha, ninguno se ha ocupado de cambios de reglamentación promulgados en aras del interés público o en cumplimiento de las normas de derecho internacional relativas al medioambiente, el desarrollo sostenible o los derechos humanos.

Sin embargo, es muy probable que dichos casos se planteen teniendo en cuenta las preocupaciones sobre el medioambiente y los derechos humanos, que no sólo se encuentran siendo objeto de consideración en el contexto de la reforma de la solución de controversias entre inversionistas y Estados, sino también en el derecho internacional público en general.

En efecto, la falta de decisiones deja abierta la cuestión de si estas cláusulas serían aplicables en los casos en que se promulgan nuevas normas para proteger los derechos humanos o para cumplir con las normas ambientales. Existen distintas teorías estudiadas por la doctrina que podrían permitir la inaplicación de estas cláusulas en caso de conflicto.

A. La nulidad de las cláusulas cuyo efecto lleva a limitaciones en el cumplimiento de las obligaciones de derechos humanos

El hecho de que la validez de las cláusulas de estabilización sea una cuestión pacífica en la jurisprudencia no excluye que sea necesario analizar las materias sobre las que el Estado puede negociar y realizar transacciones legítimamente ${ }^{47}$. Por ello,

\footnotetext{
46 Para mayor información, véase Bear Creek Mining Corporation c. Perú (2017) Dominion Minerals Corp. c. República de Panamá (2016).

47 Para mayor información, véase a Cotula (2018)
} 
algunos comentaristas sostienen que las cláusulas que menoscaban la capacidad del Estado para cumplir con su deber de proteger los derechos humanos en su territorio exceden los límites de los elementos sobre los que puede transigir el Esta$\mathrm{do}^{48}$. Por lo tanto, esos contratos serían contrarios al derecho internacional e, incluso en algunos casos, a la constitución política del Estado.

Una de las cuestiones más esenciales para determinar la validez de las cláusulas de estabilización es la determinación de la ley aplicable. Es verdad que la validez de las cláusulas de estabilización también ha sido determinada muchas veces por el derecho internacional, tratados bilaterales de inversión o incluso la lex mercatoria. Sin embargo, la mayor parte de las veces la validez de las cláusulas de estabilización ha sido determinada en virtud de las leyes nacionales. Al respecto, el profesor Erkan ha señalado lo siguiente:

The choice of governing law in international Energy investments is another key point for understanding the validity of stabilization clauses. The validity and effectiveness of stabilization clauses are closely connected with the formulation of the governing law of a contract. Therefore, in examining the validity of stabilization clauses one must consider which law is to apply to the contract containing such a clause (2010, p. 109$)^{49}$.

En tal sentido, es evidente que, en virtud de la legislación nacional, dichas cláusulas de estabilización no serán válidas. En efecto, en general, los contratos cuyo objeto es contrario a la ley se consideran nulos en virtud de las leyes contractuales nacionales ${ }^{50}$. La cuestión podría, por lo tanto, centrarse en una cuestión de derecho aplicable y en el impacto de la nulidad en virtud del derecho nacional a nivel de derecho internacional público. En el caso del Perú, por ejemplo, una cláusula de estabilización que proscribiese la potestad del Estado de proteger y resguardar los derechos humanos sería nula por vulnerar el orden público y las buenas costumbres en virtud del artículo $\mathrm{V}$ del título preliminar del Código Civil. No obstante, no nos detendremos en casos específicos sobre derecho doméstico, puesto que nuestro propósito es analizar las consecuencias de las cláusulas de estabilización centrándonos en el Derecho Internacional.

Otra manera de resolver esta cuestión es a través de la aplicación del artículo 46 de la Convención de Viena, el cual señala que el Estado podrá alegar que su consentimiento se encuentra invalidado, debido a la incompatibilidad con una norma de importancia fundamental (en este caso, la Constitución) ${ }^{51}$.

Un argumento contrario a la posición que defiende la nulidad de estas cláusulas sería la reiterada jurisprudencia que sostiene esta limitación autoimpuesta a la soberanía ${ }^{52}$. Sin embargo, la cuestión no es tan sencilla. En efecto, aunque la cláusula puede considerarse válida en general, los efectos particulares de la cláusula pueden ser contrarios a las obligaciones en materia de derechos humanos y, por lo tanto, al derecho internacional público. Algunos sectores de la doctrina abogan por hacer una interpretación adaptable para evitar resultados que no se ajusten al derecho internacional. En consecuencia, el Estado podría alegar que el TBI en cuestión debería interpretarse de manera que posibilite resultados que se encuentren en armonía con los derechos humanos y la protección del medioambiente.

\section{B. La aplicación de un enfoque evolutivo a la interpretación de las cláusulas de estabili- zación}

Otro punto de vista que se encuentra ganando fuerza en lo que respecta a las normas ambientales y la acción del Estado ha sido la aplicación de la interpretación evolutiva a estas cláusulas de estabilización (Ghene \& Brillo, 2017, p. 33). En ese sentido, algunas decisiones recientes de Derecho Internacional Público y la doctrina han abogado por una interpretación evolutiva de los tratados internacionales. Dicha interpretación permitiría

48 Para mayor información véase a Ghene y Brillo (2017).

49 "La elección en la ley que rige las inversiones internacionales en energías es otro punto clave para entender la validez de las cláusulas de estabilización. La validez y eficacia de las cláusulas de estabilización están estrechamente conectadas con la formulación de la ley que rige sobre un contrato. Por lo tanto, al examinar la validez de las cláusulas de estabilización uno debe considerar cuál ley es la que debe aplicar al contrato que contiene dicha cláusula" [traducción libre].

50 Por ejemplo, véanse los artículos 1271 y 1272 del Código Civil español.

51 En ese sentido, el artículo 46 de la Convención de Viena sobre Derecho de los Tratados establece lo siguiente:

1. El hecho de que el consentimiento de un Estado en obligarse por un tratado haya sido manifiesto en violación de una disposición de su derecho interno concerniente a la competencia para celebrar tratados no podrá ser alegado por dicho Estado como vicio de su consentimiento, a menos que esa violación sea manifiesta y afecte a una norma de importancia fundamental de su derecho interno. 2. Una violación es manifiesta si resulta objetivamente evidente para cualquier Estado que proceda en la materia conforme a la práctica usual y de buena fe.

52 Para mayor información, véase a Faruque (2006) y a Frank (2014). 
flexibilizar el principio de pacta sunt servanda ${ }^{53}$. De hecho, en los sectores de energía y recursos naturales es particularmente interesante el hecho de que este principio se ha aplicado especialmente en casos relacionados con preocupaciones ambientales.

Otra variante de esta doctrina es la representada por decisiones internacionales como aquella respecto del Proyecto Gabčikovo-Nagymaros que ordenó la renegociación obligatoria de las condiciones del contrato objeto de la disputa ${ }^{54}$ (Hungría $c$. Eslovaquia, 1997). Es importante señalar que ésta es la tendencia que también está prevaleciendo en las actuales cláusulas de estabilización, en que las cláusulas de equilibrio económico que prevén la renegociación obligatoria se convierten cada vez más en la regla ${ }^{55}$.

\section{REFLEXIONES FINALES}

Las cláusulas de estabilización pueden limitar la capacidad de los Estados para regular en el interés público, especialmente cuando estas cláusulas se firman con empresas de los sectores de la energía y los recursos naturales. Sin embargo, dicha limitación de la potestad regulatoria dependerá, en gran medida, de la redacción concreta de la cláusula. Por lo tanto, es necesario prestar más atención al proceso de negociación y a las condiciones finales incluidas en los contratos de inversión con los Estados (y por los Estados) para evaluar esta crítica en lugar de centrarse únicamente en la mera inclusión de la cláusula en un contrato.

De hecho, del análisis de las tendencias actuales en las cláusulas de estabilización, y en particular en la región de América Latina y el Caribe, todo parece indicar que las cláusulas de estabilización generalmente dejan suficiente espacio para que los Estados se mantengan actualizados con las nuevas normas ambientales y otras normas de interés público en relación con sus inversionistas extranjeros. Los contratos de inversión actuales muestran una tendencia hacia un enfoque más equilibrado entre los derechos económicos de los inversionistas y la soberanía de los Estados. Es probable que esta tendencia continúe, habida cuenta de los debates actuales sobre la reforma del sistema de solución de controversias entre inversionistas y Estados, que ponen de relieve que el equilibrio entre los derechos económicos y la sostenibilidad es una cues- tión fundamental. Por último, el regulatory chill dependerá a largo plazo en la probabilidad de que el Estado enfrente una responsabilidad sustancial después de un cambio regulatorio, habida cuenta de las pocas chances que hay de que se dicte un laudo de specific performance ${ }^{56}$.

La evolución de la jurisprudencia que interpreta y hace cumplir estas cláusulas será, por lo tanto, esencial para evaluar el impacto de estas cláusulas en el fomento del interés público. Lamentablemente, hasta la actualidad ningún laudo ha abordado un tema tan importante como la licitud de las acciones estatales destinadas a regular el interés público en presencia de una cláusula de estabilización.

De iniciarse arbitrajes CIADI como consecuencia de la suspensión de los peajes en el Perú decretada mediante la Ley 31018, en la medida que varios de las concesiones se encuentran estabilizadas en virtud de contratos-ley, nos podríamos encontrar con los primeros laudos que se pronunciarían sobre la legalidad de acciones estatales adoptadas con el propósito de resguardar el interés público a pesar de la existencia de una cláusula de estabilización.

En cualquier caso, si bien es verdad que el estándar de trato justo y equitativo no otorga un derecho de estabilidad regulatoria por sí misma, consideramos que la acreditación del incumplimiento de una cláusula de estabilización es un argumento poderoso que podrían articular los inversionistas para demostrar que el trato justo y equitativo se ha visto vulnerado. En efecto, no cabe la menor duda de que la suscripción de una cláusula de estabilización crea legítimas expectativas en el inversionista.

Esto no significa, sin embargo, que el Estado se encuentra impedido de regular en presencia de una cláusula de estabilización cuando la tutela de los derechos humanos así lo exige. Por supuesto que se encuentra legitimado para hacerlo. En el caso de los peajes en el Perú, por ejemplo, podría argumentarse que resultaba indispensable que el Estado suspenda el cobro de los peajes a fin de tutelar el derecho a la salud de todos los ciudadanos. No obstante, ello no implica que el Estado se encuentra exonerado de responsabilidad. Al haber incumplido una cláusula de estabilización, debe indemnizar al inversionista por los daños y perjuicios ocasionados.

\footnotetext{
53 Para mayor información, véase a Para mayor información, véase a Ghene y Brillo (2017).

54 Para mayor información, véase la decisión de la Corte Internacional de Justicia respecto del caso proyecto GabčikovoNagymaros Project (Hungría c. Eslovaquia).

55 Para mayor información, véase a Shemberg (2009).

56 Para mayor información, véase a Sinclair y Triantafilou (2017).
} 
No consideramos que sea saludable interpretar que no se debe pagar ninguna compensación a los inversionistas porque el derecho internacional de los derechos humanos debe primar sobre los tratados bilaterales de inversión. Una interpretación como esta última no solamente ahuyentaría la inversión extranjera, sino que incluso quebraría la lógica y la funcionalidad de las cláusulas de estabilización, despojándolas así de todo sentido.

En definitiva, resulta indudable de que existe una tensión insoportable entre las cláusulas de estabilización, la soberanía de los Estados y los derechos humanos. No creemos que pueda afirmarse, prima facie, que uno debe primar sobre el otro. En efecto, el análisis debe ser absolutamente casuístico, y el ejercicio a realizar debe ser siempre uno de ponderación. Nos encontramos ante uno de esos típicos casos en que todos los valores en juego deben ser maximizados en su conjunto.

\section{REFERENCIAS}

Amnistía Internacional (2006). Human Rights, Trade and Investment Matters. https://www. amnestyusa.org/files/pdfs/hrtradeinvestmentmatters.pdf

Boudreaux, K., \& Neyman, Y. (2015). Operational Guidelines for Responsible Land-Based Investment. https://www.land-links.org/wp-content/uploads/2016/09/USAID_Operational_ Guidelines_updated.pdf

Cameron, P. (2006). Stabilisation in Investment Contracts and Changes of Rules in Host Countries: Tools for Oil \& Gas Investors. Association of International Petroleum Negotiators (AIPN). https://www.international-arbitration-attorney.com/wp-content/uploads/arbitrationlaw4-Stabilisation-Paper.pdf

Cotula, L. (2008). Regulatory Takings, Stabilization Clauses and Sustainable Development. Best practices in promoting investment for development (paper 2008/28). OECD VII Global Forum on International Investment. https://www.oecd.org/investment/globalforum/40311122.pdf

(2018). Reconsidering Sovereignty, Ownership and Consent in Natural Resource Contracts: From Concepts to Practice. En Bungenberg, M., Krajewski, M, Philipp Terhechte, J., \& Ziegler, A. (Eds.). European Yearbook of International Economic Law 2018, 143-174. https://link.springer.com/book/10.1007/978-3-319-97752-2
Crockett, A. (2011). Stabilisation clauses and sustainable development: Drafting for the future. En Brown, C. \& Miles, K. (Eds.). Evolution in Investment Treaty Law and Arbitration. Cambridge University Press.

Emeka, J. (2008). Anchoring Stabilization Clauses in International Petroleum Contracts. International Lawyer, 42(4), 1317-1338. https://scholar.smu.edu/cgi/viewcontent. cgi?article $=1227 \&$ context $=$ til

Erkan, M. (2010). International Energy Investment Law: Stability through Contractual Clauses, Association of International Petroleum Negotiators. Kluwer Law International.

Faruque, A. (2006). Validity and Efficacy of Stabilisation Clauses: Legal Protection versus Functional Value. Journal of International Arbitration, 23(4), 317-336. https://www.researchgate. net/publication/333433993_Validity_and_Efficacy_of_Stabilisation_Clauses_Legal_Protection_versus_Functional_Value

Frank, S. (2014). Stabilisation Clauses and Sustainable Development in Developing Countries [Tesis para optar al grado de Doctor en Filosofía, Universidad de Nottingham]. http://eprints.nottingham.ac.uk/14466/1/PhD_Thesis.pdf

Ghene, K., \& Brillo, R. (2017). Stabilization Clauses in International Investment Law: Beyond Balancing and Fair and Equitable Treatment. Institute of Economic Law Transnational Economic Law Research Center (TELC) de la Facultad de Derecho de la Universidad Martín Lutero de Halle-Wittenberg. http://telc.jura.uni-halle. de/sites/default/files/BeitraegeTWR/Heft\%20 143.pdf

Gjuzi, J. (2018). Stabilization Clauses in International Investment Law: A sustainable development approach. Springer International Publishing.

Halabi, S.F. (2011). Efficient Contracting between Foreign Investors and Host States: Evidence from Stabilization Clauses. Northwestern Journal of International Law and Business, (33). https:// scholarship.law.missouri.edu/cgi/viewcontent. cgi?article $=1649 \&$ context $=$ facpubs

Nathanson, R. (2012). The Revocation of CleanEnergy Investment Economic-Support Systems as Indirect Expropriation Post-Nykomb: A Spanish Case Analysis. lowa Law Review, (98), 863904. http://dx.doi.org/10.2139/ssrn.2063294 
Nelson, A. (9 de noviembre de 2011). Investments in the deep freeze? Stabilization clauses in investment contracts [Kluwer Arbitration Blog] http://arbitrationblog.kluwerarbitration. com/2011/11/09/investments-in-the-deepfreeze-stabilization-clauses-in-investment-contracts/

Nwaokoro, J. (2014). Enforcing stabilization of international energy contracts. Journal of World Energy Law \& Business, 1(3), 103-110. https:// doi.org/10.1093/jwelb/jwp027

Maniruzzaman, A.F.M. (2008). The pursuit of stability in international energy investment contracts: A critical appraisal of the emerging trends. Journal of World Energy Law \& Business, 1(2). https://www.researchgate.net/ publication/31402431_The_pursuit_of_stability_in_international_energy_investment_ contracts_A_critical_appraisal_of_the_emerging_trends

Oficina del Alto Comisionado de los Derechos Humanos de las Naciones Unidas (2015). Principios de Contratación Responsable: Integración de la Gestión de los Riesgos Relacionados con los Derechos Humanos en las Negociaciones entre Estados e Inversiones. https://www.ohchr.org/Documents/Publications/Principles_ ResponsibleContracts_HR_PUB_15_1_SP.pdf

Peter, W. (1995). Arbitration \& Renegotiation of International Investment Agreements. Kluwer Law International.

Schreurer, C. (2004). Non-Pecuniary Remedies in ICSID Arbitration. Arbitration International, 20(4), 325-332. https://www.univie.ac.at/intlaw/wordpress/pdf/71_cspubl_71.pdf

Shemberg, A. (2009). Stabilization Clauses and Human Rights. A research project conducted for IFC and the United Nations Special Representative of the Secretary-General on Business and Human Rights. International Finance Corporation (IFC). https://www.ifc.org/wps/ wcm/connect/0883d81a-e00a-4551-b2b946641e5a9bba/Stabilization\%2BPaper.pdf?M OD=AJPERES\&CACHEID=ROOTWORKSPACE0883d81a-e00a-4551-b2b9-46641e5a9bbajqeww2e

Sheppard, A.W., \& Crockett, A. (2011). Are Stabilization Clauses a Threat to Sustainable Development? En Cordonier Segger, A.C., Gehring, M., \& Newcombe, A. (Eds.). Sustainable Development in World Investment Law (Global Trade Law), 333-350. Kluwer Law International.
Sinclair, A.C., \& Triantafilou, E. (2017). Specific Performance under Commercial Contracts with Sovereign States. Journal of International Arbitration, 34(5), 747-774. https://www.researchgate.net/publication/322064544_Specific_performance_under_commercial_contracts_with_sovereign_states

Umirdinov, A. (2015). The End of Hibernation of Stabilization Clause in Investment Arbitration: Reassessing its Contribution to Sustainable Development. Denver Journal of International Law \& Policy, 43(4), 455-487. https:// digitalcommons.du.edu/cgi/viewcontent. cgi?article $=1075 \&$ context $=$ djilp

\section{LEGISLACIÓN, JURISPRUDENCIA Y OTROS DOCU- MENTOS LEGALES}

AES Summit Generation Limited y AES-Tisza Erömü Kft c. República de Hungría, Caso CIADI No. ARB/07/22, Laudo (25 de septiembre de 2010).

AGIP SPA c. República Popular del Congo, Caso CIADI No. ARB/77/1, Laudo (30 de noviembre de 1979)

Anglo American PLC c. República Bolivariana de Venezuela, Caso CIADI No. ARB(AB)/14/1, Laudo (18 de junio de 2019), https://www.italaw. com/cases/2513

Antoine Goetz et consorts c. República de Burundi, Caso CIADI No. ARB/95/3, Laudo (10 de febrero de 1999), https://www.italaw.com/cases/508

Bear Creek Mining Corporation c. Perú, Caso CIADI No. ARB/14/21, Laudo (30 de noviembre de 2017).

Belenergía S.A. c. Italia, Caso CIADI No. ARB/15/40, Laudo (6 de agosto de 2019).

Burlington Resources Inc. c. Ecuador, Caso CIADI No. ARB/08/5, Laudo (14 de diciembre de 2002)

CMS Gas Transmission Company c. República de Argentina, Caso CIADI No. ARB/01/8, Laudo (12 de mayo de 2005), https://www.italaw. com/cases/288

Código Civil [CC], B.O.E. n. 206, 24 de julio de 1889 (España).

Código Civil [CC], Diario Oficial El Peruano, 25 de julio de 1984 (Perú).

Decreto Supremo 008-2020-EF. Decreto Supremo que autoriza el Crédito Suplementario en el Presupuesto del Sector Público para el Año 
Fiscal 2020 a favor de diversos Gobiernos Locales para la continuidad de inversiones. Diario Oficial El Peruano, 30 de enero de 2020 (Perú).

Decreto Supremo 037-2009-EF. Decreto Supremo que otorga la garantía del Estado en respaldo de declaraciones, seguridades y obligaciones contenidas en el Contrato de Concesión de los Tramos Viales de la Red Vial N4, a celebrarse con Autopista del Norte S.A.C. Diario Oficial El Peruano, 14 de febrero de 2009 (Perú).

Decreto Supremo 124-2005-EF. Decreto Supremo que otorga garantía del Estado en respaldo de declaraciones, seguridades y obligaciones obtenidas en el Contrato de Concesión del Tramo Vial Puente Pucusana - Cerro Azul - Ica, a celebrarse con COVIPERU S.A. Diario Oficial El Peruano, 17 de septiembre de 2005 (Perú).

Decreto Supremo 177-2002-EF. Decreto Supremo que otorga garantía del Estado en respaldo de seguridades, obligaciones y otros, contenidas en contrato de concesión del tramo Ancón - Huacho - Pativilca de la Carretera Panamericana Norte. Diario Oficial El Peruano, 20 de noviembre de 2002 (Perú).

Decreto Supremo 180-2009-EF. Decreto Supremo que otorga garantía del Estado de la República del Perú a la empresa concesionaria Vial del Sol S.A. Diario Oficial El Peruano, 15 de agosto de 2009 (Perú).

Decreto Supremo 192-2010-EF. Diario Oficial El Peruano, 11 de septiembre de 2010 (Perú).

Dominion Minerals Corp. c. Panamá, Caso CIADI No. ARB/16/13, Laudo (29 de marzo de 2016).

Duke Energy International Peru Investments No. 1 Ltd. c. República del Perú, Caso CIADI No. ARB/03/28, Laudo (18 de agosto de 2008), https://www.italaw.com/cases/3399

Eiser Infrastructure Limited y Energía Solar Luxembourg S.A.R.I. c. España, Caso CIADI No. ARB/13/36, Laudo (4 de mayo de 2017).

Franck Charles Arif c. República Moldova, Caso CIADI No. ARB/11/23, Laudo (8 de abril de 2013), https://www.italaw.com/cases/1846
I.C.Q. Europe Investments Limited c. República Checa, Caso PCA No. 2014-22, Laudo (15 de mayo de 2019).

Ley 29785. Ley del derecho a la consulta previa a los pueblos indígenas u originarios, reconocido en el Convenio 169 de la Organización Internacional del Trabajo. Diario Oficial El Peruano, 7 de septiembre de 2011 (Perú).

Ley 31018. Ley que suspende el cobro de peajes en la red vial nacional, departamental y local concesionada durante el Estado de Emergencia Nacional. Diario Oficial El Peruano, 7 de mayo del 2020 (Perú).

LETCO (Liberian Easter Timber Corporation) c. República de Liberia, Caso CIADI No. ARB/83/2, Laudo (31 de marzo de 1986), https://www. italaw.com/cases/3545

Marvin Roy Feldman Karpa c. México, Caso CIADI No. ARB(AF)/99/1, Laudo (16 de diciembre de 2002).

Organización Mundial del Comercio [OMC], United States - Import Prohibition of Certain Shrimp and Shrimp Products, Exp. WT/DS58/AB/R, 6 de noviembre de 1998.

Organización Mundial del Trabajo, Convenio sobre pueblos indígenas y tribales en países independientes, Convenio No. 169, 27 de junio de 1989.

Parkerings-Compagniet AS c. Lituania, Caso CIADI No. ARB/05/08, Laudo (11 de septiembre de 2017).

Proyecto de Gabčikovo-Nagymaros (Hung. c. Eslovaquia), C.I.J. Rep. 1997.

Revere Copper \& Brass Inc. c. Overseas Private Investment Corporation, Caso AAA No. 1610013776, Laudo (24 de agosto de 1978).

Texaco Overseas Petroleum Company y California Asiatic Oil Company c. República Árabe de Libia, Caso YCA No. 1979, Laudo (19 de enero de 1977).

Total S.A. c. Argentina, Caso CIADI No. ARB/04/01, Laudo (27 de diciembre de 2010). 